\title{
PENERAPAN MEDIA BONEKA TANGAN UNTUK MENINGKATKAN KERETAMPILAN BERCERITA SANTRI
}

\begin{abstract}
Desty Pratiwi
Mahasiswa Prodi PAI FITK UIN

Raden Fatah Palembang
\end{abstract}

Abdurrahmansyah Dan Sukirman

Dosen UIN Raden Fatah Palembang

Destypratiwi1996@gmail.com

\begin{abstract}
Abstrak
Hand puppet media is a way to improve Santri's storytelling skills. What is seen from the first problem What is the skill of storytelling of the control class santri that does not use puppet media. Second What is the skill of storytelling of students in the experimental class using hand puppet media. This research is a quantitative study, the data collection techniques in this study used the method of test observation and documentation, to analyze the data using the TSR test. The data of this study were collected from the number of students of class III Ibtidaiyah Indralaya Madrasah taken as much as $20 \%$ of the total number of santri namely as many as 132 students and obtained 50 respondents, starting from class III A and class III C

Based on the results obtained from the field and calculations using the TSR Test, it can be concluded that: firstly the control skills of the students in the control class in the high categorized learning process were 3 santri (18.52\%.) And the moderate categorized values were 8 santri (59.26\%) As for the low categorized values as many as 16 santri (22.22\%) as for the two experimental students' storytelling skills in the learning process it was categorized as high as 5 santri (21.7\%) and medium ones as many as 14 santri (60.8\%) and categorized low as many as 4 santri (17.39\%),

. To find out how the difference is using the $r_{X Y}$ formula. from the results of the $X Y$ count, it proves that the results of $r$ count are greater than $r$ table both at the significant level of $5 \%$ and $1 \%$ (20.1 <4.69> 2.68). This shows that "there is a significant difference between the storytelling skills of the experimental class and the control class with the application of hand puppet media in class III of Al-Ittifaqiah Indralaya Ibtidaiyah Madrasah.
\end{abstract}

Keywords: Hand Puppet Media and Santri Storytelling Skills 


\section{PENDAHULUAN}

Kata media berasal dari kata medius dalam referensi lain disebut dengan kata medium yang memiliki arti tengah, perantara, dan pengantar. Media dapat berupa manusia, materi, kejadian, atau segala bentuk yang dapat membangun suatu kondisi yang baik untuk belajar sehingga membuat siswa mampu membuat pengetahuan, keterampilan atau sikap. ${ }^{1}$

Mendefinisikan media boneka tangan sebagai benda tiruan dari bentuk manusia atau binatang sebagai media pendidikan, dalam penggunaannya boneka dimainkan dalam bentuk sandiwara boneka. ${ }^{2}$ Menurut Nana Sudjana dan Ahmad Rivai menyatakan bahwa boneka tangan adalah boneka yang digerakkan dari bawah oleh seseorang yang tangannya dimasukkan ke bawah pakaian boneka tersebut ${ }^{3}$. Berdasarkan pengertian media pembelajaran yang telah dipaparkan di atas, jika dikaitkan dengan pengertian boneka tangan dapat disimpulkan media boneka tangan adalah suatu media tiruan binatang yang digerakkan dari bawah oleh seseorang yang tangannya dimasukkan ke bawah pakaian boneka tersebut.

Menurut WJS Purwadarmito keterampilan berasal dari kata dasar terampil yang artinya cekatan, cakap mengerjakan sesuatu. Keterampilan berarti kecekatan, kecakapan atau kemampuan untuk melakukan sesuatu dengan baik dan cermat. ${ }^{4}$

Haryadi dan Zamzami mengungkapkan bahwa berbicara secara umum dapat diartikan suatu penyampaian maksud (ide, pikiran, isi hati) seseorang kepada orang lain dengan menggunakan bahasa lisan sehingga maksud tersebut dapat dipahami oleh orang lain. 5

Menurut Saleh Abbas berbicara merupakan proses berkomunikasi dengan mempergunakan suara yang dihasilkan oleh alat ucap manusia yang di dalamnya

\footnotetext{
${ }^{1}$ Ali Hamzah dan Muhlisrarini, Perencanaan Dan Strategi Pembelajaran Matematika, (Jakarta: Rajawali Pers, 2014), hlm: 95

${ }^{2}$ Daryantio, media pembelajaran, (Yogyakarta: Gava Media, 2016).hlm. 33

${ }^{3}$ Nana Sudjanah dan Ahmad Rivai, Media Pengajaran, (Bandung: CV. Sinar Baru 1991),hln.188

${ }^{4}$ WJS Poerwodarminto. Pusat Pembinaan dan Pengembangan Bahasa Depdikbud. (Jakarta : Balai Pustaka, 1984), hln.1088

5 Haryadi dan Zamzami, PeningkatanKeterampilan Berbahasa Indonesia. (Jakarta : Direktorat Jendral Pendidikan Tinggi, 1997), hlm.54
} 
terjadi pemindahan pesan dari suatu sumber ke tempat yang lain. ${ }^{6}$ Menurut Djago Tarigan, dkk juga menyatakan bahwa berbicara adalah keterampilan menyampaikan pesan melalui bahasa lisan. ${ }^{7}$

Menurut St. Y. Slamet mengemukakan tujuan pembelajaran berbicara di kelaskelas awal ini dapat dirumuskan sebagai berikut: 1. Belajar menghasilkan buah pikiran dan perasaan sendiri dengan bahasa yang sebenarnya, sopan dan jelas. 2 . Melatih anak menghasilkan pikiran, perasaan, dan kemauannya dengan bahasa sederhana yang baik dan benar. 3. Siswa mampu mengungkapkan kata dengan lafal yang benar. 4. Siswa mampu mengucapkan atau mengatakan kalimat dengan. 4. intonasi yang wajar dan sesuai dengan konteksnya. 5.Siswa mampu berinteraksi dan menjalin hubungan dengan orang lain secara lisan. 6 Siswa memiliki kepuasan dan kesenangan berbicara. ${ }^{8}$

Menurut Ahmad Rofi'uddin dan Darmiyati Zuchdi pengembangan keterampilan berbicara di sekolah dasar terutama kelas 3 adalah secara vertikal tidak secara horizontal, maksudnya pada awalnya anak-anak sudah dapat mengungkapkan pesan secara langsung tetapi belum sempurna. Pengembangan keterampilan berbicara tersebut harus menggunakan kegiatan pembelajaran yang melibatkan siswa agar peningkatan keterampilan berbicara siswa lebih bermakna. ${ }^{9}$

Saleh Abbas menjelaskan ada beberapa kegiatan pembelajaran keterampilan berbicara untuk sekolah dasar. yaitu Menirukan ucapan, Menceritakan hasil pengamatan, Percakapan, Mendeskripsikan, Pertanyaan menggali, Bercerita, Berwawancara dan melaporkan hasilnya, Berpidato, dan Diskusi. ${ }^{10}$

Adapun definisi dari mata pelajaran Sejarah Kebudayaan Islam tertulis dalam Peraturan Menteri Agama, menyatakan bahwa sejarah kebudayaan Islam di Madrasah

${ }^{6}$ Saleh Abbas, Pembelajaran Bahasa Indonesia yang Efektif di Sekolah Dasar. (Jakarta : Direktorat Jendral Pendidikan Tinggi,2006), hlm.23

${ }^{7}$ Djago Tarigan, dkk, Materi Pokok Pendidikan Bahasa Indonesia I . (Jakarta : P2LPTK PT Depdikbud, 1990), hlm.149

${ }^{8}$ Mudini dan Salamat Purba. Pembelajaran Berbicara.( Jakarta: Depdiknas, 2007). hlm.79

9 Ahmad Rofi'uddin \& Darmiyati Zuhdi., Pendidikan Bahasa dan Sastra Indonesia di Kelas Tinggi. (Jakarta: Depdikbud RI, 1998). hlm. 32

${ }^{10}$ Saleh Abbas, Pembelajaran Bahasa Indonesia yang Efektif di Sekolah Dasar. (Jakarta : Direktorat Jendral Pendidikan Tinggi, 2006.), hlm. 85 
Ibtidaiyah merupakan salah satu mata pelajaran yang menelaah tentang asal-usul, perkembangan, peranan kebudayaan/peradaban Islam di masa lampau, secara substansial mata pelajaran sejarah kebudayaan Islam memiliki kontribusi dalam memberikan motivasi kepada peserta didik untuk mengenal, memahami, menghayati, sejarah kebudayaan islam, yang mengandung nilai-nilai kearifan yang dapat digunakan untuk melatih kecerdasan, membentuk sikap, watak dan kepribadian peserta didik. ${ }^{11}$

Adapun tujuan dari Mata pelajaran Sejarah Kebudayaan Islam di Madrasah Ibtidaiyah peminatan Ilmu-ilmu keagamaan bertujuan untuk: Membangun kecerdasan peserta didik tentang pentingnya mempelajari landasan ajaran, nilai-nilai dan normanorma Islam yang telah dibangun oleh Rasulullah SAW dalam rangka mengembangkan kebudayaan dan peradaban islam. Membangun kesadaran peserta didik tentang pentingnya waktu dan tempat yang merupakan sebuah proses dari masa lampau, masa kini dan masa depan Melatih daya kritis peserta didik untuk memahami fakta sejarah secara benar dengan didasarkan pada pendekatan ilmiah. Menumbuhkan apresiasi dan penghargaan peserta didik terhadap peninggalan sejarah Islam sebagai bukti peradaban umat Islam di masa lampau. Mengembangkan kemampuan peserta didik dalam mengambil ibrah dari peristiwa-peristiwa bersejarah (Islam), meneladani tokoh-tokoh berprestasi, dan mengaitkannya dengan fenomena sosial, budaya, politik, ekonomi, iptek, dan seni, dan lain-lain untuk mengembangkan kebudayaan dan peradaban islam. $^{12}$

Media boneka tangan merupakan cara untuk meningkatkan keterampilan bercerita santri, yang mana melihat dari permasalahan yang pertama bagaimana keterampilan bercerita santri kelas kontrol yang tidak menggunakan media boneka. Kedua bagaimana keterampilan bercerita santri kelas eksperimen yang menggunakan media boneka tangan. Ketiga bagaimana hasil keterampilan bercerita santri kelas kontrol tidak menggunakan media boneka tangan dan kelas eksperimen yang

11 Kementrian Agama, Peraturan Mentri Agama Republik Indonesia Tentang Kurikulum Madrasah 2013 Mata Pelajaran Pendidikan Agama Islam dan Bahasa Arab, No.000912, th. 2013, p. 49

${ }^{12}$ Kementrian Agama, Op.Cit., p. 53 
Vol. 1, No. 3 (Agustus 2019): 328-350

menggunakan media boneka tangan pada mata pelajaran sejarah kebudayaan Islam pada materi peristiwa kelahiran Rasulullah di Madrasah Ibtidaiyah al-Ittifaqiah Indralaya.

\section{METODE PENELITIAN}

Metodologi penelitian adalah proses atau cara ilmiah untuk mendapat data yang akan digunakan untuk keperluan penelitian. Terdapat beberapa cara untuk melakukan penelitian. Diantaranya, populasi, sampel, jenis dan sumber data, teknik pengumpulan data dan teknik analisis data. Populasi dalam penelitian ini yang menjadi populasi adalah seluruh santri kelas III Madrasah Ibtidaiyah Al-Ittifaqiah Indralaya. Dan dalam penelitian ini, peneliti membatasi pada santri kelas III dengan jumlah 132 Santri. Akan tetapi karena keterbatasan penulis, maka penulis berusaha untuk memperkecil subyek penelitian dengan cara mengambil sampel. Seperti pendapat Suharsimi Arikunto ${ }^{13}$. Dan penulis menggunakan teknik Random Sampling yaitu: peneliti memberi hak yang sama kepada setiap subyek per-kelas untuk memperoleh kesempatan dipilih menjadi sampel.

Data yang diperlukan dalam penelitian ini, yaitu data kuantitatif statistik. ${ }^{14}$ Data kuantitatif adalah data yang dinyatakan berupa angka yakni data jumlah guru dan karyawan, jumlah siswa, skor metode atau media boneka tangan skor hasil keterampilan bercerita santri, skor media boneka tangan terhadap keterampilan bercerita santri di kelas III Madrasah Ibtidaiyah Al-Ittifaqiah Indralaya. Dan Sumber data adalah tempat dari mana memperoleh data. Data yang dikumpulkan dalam penelitian meliputi data primer dan data sekunder. Data primer adalah sumber data yang langsung memberikan data kepada pengumpul data. Sedangkan data sekunder adalah sumber yang tidak langsung memberikan data kepada pengumpulan data. ${ }^{15}$

Menurut Sugiyono teknik pengumpulan data merupakan langkah yang paling strategis dalam penelitian, karena tujuan utama dari penelitian adalah mendapatkan

\footnotetext{
${ }^{13}$ Ibid., hlm. 94.

${ }^{14}$ Ibid., hlm. 191

${ }^{15}$ Sugiyono, Metode Penelitian Kuantitatif, Kualitatif dan R\&D, (Bandung: CV. Alfabeta, 2011), hlm. 225.
} 
data. Teknik pengumpulan data yang peneliti pilih untuk dijadikan dalam penelitian ini menggunakan beberapa metode, yaitu Observasi. Menurut Anas Sudijono menyatakan Observasi merupakan cara menghimpun bahan-bahan keterangan (data) yang dilakukan dengan mengadakan pengamatan dan penelitian secara sistematis terhadap fenomena-fenomena yang sedang dijadikan sasaran pengamatan. ${ }^{16}$ Dan Dokumentasi, menurut Sugiyono bahwa dokumentasi merupakan catatan peristiwa yang sudah berlalu. Dokumen bisa berbentuk tulisan, gambar atau karya-karya monumental dari seorang. Dokumen yang berbentuk tulisan misalnya: catatan harian, sejarah kehidupan, cerita, biografi. Dokumen berbentuk gambar misalnya: foto, gambar hidup, sketsa dan lain-lain. Dokumen yang berbentuk karya misalnya: karya seni yang berupa gambar, patung, film dan lain-lain. Studi dokumen merupakan pelengkap dari penggunaan metode observasi dalam penelitian kuantitatif. ${ }^{17}$

Menurut Sugiyono Analisis data adalah proses mencari dan menyusun secara sistematis data yang diperoleh dari observasi, dokumentasi, dan bahan-bahan lain. Sehingga dapat mudah dipahami, dan temuannya dapat diinformasikan kepada orang lain. ${ }^{18}$ Sesuai dengan pembahasan tersebut, maka peneliti dalam menganalisa masalah dengan menggunakan metode Kuantitatif Deskriptif Statistic (eksperimen). Untuk menganalisis data yang terkumpul, maka diperlukan adanya analisis yang sesuai dengan sifat jenis yang ada yaitu menggunakan teknik analisis: Untuk menjawab permasalahan yang pertama yaitu tentang media Boneka Tangan dan permasalahan yang kedua tentang keterampilan bercerita santri di kelas III Madrasah Ibtidaiyah AlIttifaqiah Indralaya. peneliti menggunakan analisa statistik sederhana yaitu menggunakan rumus Presentase, dengan rumus TSR. Untuk Mengetahui menggunakan analisa Statistik Product Moment dengan menggunakan rumus angka kasar penggunaan data statistik product moment terformulasikan sebagai berikut:

$$
r x y=\frac{\mathrm{N} \sum \mathrm{xy}-\left(\sum \mathrm{x}\right)\left(\sum \mathrm{y}\right)}{\sqrt{\left(\mathrm{N} \sum \mathrm{x}^{2}\right)-}\left(\sum \mathrm{x}^{2}\right)\left(\mathrm{N} \sum \mathrm{y}^{2}\right)-\left(\sum \mathrm{y}\right)^{2}}
$$

16 Anas Sudijono, Pengantar Evaluasi Pendidikan. (Jakarta: PT Raja Grafindo Persada, 2015), hlm. 76.

${ }^{17}$ Sugiyono, Metode Penelitian Kuantitatif, Kualitatif dan R\&D...., hlm. 240.

${ }^{18}$ Ibid. hlm. 244. 
Vol. 1, No. 3 (Agustus 2019): 328-350

Dengan dasar rumusan di atas, maka dapat diperoleh nilai korelasi nilai (rxy). Nilai " $r$ " kemudian dikonsultasikan dengan " $r$ ' product moment dalam tabel. Untuk mengetahui pengesahan hasil ini digunakan taraf signifikan 5\% dan 1\%, jika nilai yang diperoleh sama atau lebih besar dari " $\mathrm{r}$ " dalam tabel, maka nilai tersebut signifikan.

\section{HASIL DAN PEMBAHASAN}

\section{A. Hasil Keterampilan Bercerita Santri Dengan Menggunakan Media Boneka Tangan}

Hasil keterampilan Bercerita Santri Dengan Menggunakan Media Boneka Tangan yang didapat dari hasil tes beberapa aspek keterampilan yang diberikan kepada santri kelas III Madrasah Ibtidaiyah Indralaya sebanyak 23 responden dengan nama-nama sebagai berikut:

Tabel. 1

Nama Responden kelas III A

Madrasah Ibtidaiyah Indralaya Ogan Ilir Sumatera Selatan

\begin{tabular}{|c|l|c|}
\hline No & \multicolumn{1}{|c|}{ Nama-nama Santri } & Jenis Kelamin \\
& & \\
\hline \hline 1 & Aditya Tama & Laki-laki \\
\hline 2 & Alfin Syahrin Firza & Laki-laki \\
\hline 3 & M. Azriansyah & Laki-laki \\
\hline 4 & M. Nuzri Az-Zakkiy & Laki-laki \\
\hline 5 & Muhammad Alfaroby & Laki-laki \\
\hline 6 & Muhammad Al-Fares Andestra & Laki-laki \\
\hline 7 & Muhammad Amru Yafi & Laki-laki \\
\hline 8 & Muhammad Maulana Akbar & Laki-laki \\
\hline 9 & Muhammad Naufal Fawwazz Aryanto & Laki-laki \\
\hline 10 & Nizam Arif Rahman Hakim & Laki-laki \\
\hline 11 & Rifki Abian & Laki-laki \\
\hline 12 & Aisyah Aulia & Perempuan \\
\hline 13 & Bunga Mei Dinah & Perempuan \\
\hline 14 & Chintia Putri Awaliya & Perempuan \\
\hline 15 & Dina Alfiya Nur Rahmah & Perempuan \\
\hline 16 & Fairuz Azmi Dzakirah & Perempuan \\
\hline & & \\
\hline
\end{tabular}




\begin{tabular}{|c|l|c|}
17 & Hafizah Futri Sulaiman & Perempuan \\
\hline 18 & Keisyah Alfi Ramadhani & Perempuan \\
\hline 19 & Naila Hilyatil Asfiya & Perempuan \\
\hline 20 & Naura Kholidah & Perempuan \\
\hline 21 & Nur Jannatin Aliyah & Perempuan \\
\hline 22 & Tazkiya Zahrani Fatima & Perempuan \\
\hline 23 & Zafira & Perempuan \\
\hline
\end{tabular}

Responden dalam peneliti ini ialah santriwan-santriwati kelas III Madrasah Ibtidaiyah Idralaya pada mata pelajaran Sejarah Kebudayaan Islam yang berjumlah 23 santri, yang terdiri dari siswa laki-laki sebanyak 10 orang, sedangkan perempuan atau santriwati 13 orang. Jumlah tes yang diambil dan digunakan oleh peneliti pada penelitian ini adalah tes mengenai empat aspekaspek keterampilan bercerita santri.

Untuk mendapatkan nilai mengenai hasil ketrampilan santri saat proses pembelajaran mata pelajaran Sejarah Kebudayaan Islam materi Peristiwa kelahiran Rasulullah SAW di Madrasah Ibtidaiyah Indralaya Ogan Ilir Sumatra Selatan, peneliti menggunakan tes yaitu berupa tes empat aspek keterampilan bercerita yang diberikan kepada santriwan dan santriwati yang berjumlah 23, berikut ini hasil keterampilan bercerita santri sesudah menggunakan Media Boneka Tangan. Dari hasil test yang telah diberikan kepada 23 orang santri, maka diperoleh data hasil belajar dengan diterapkannya media pembelajaran Boneka Tangan sebagai berikut:

Tabel. 2

Hasil Penilaian Keterampilan Bercerita Santri Dengan Menggunakan Media Boneka Tangan

\begin{tabular}{|c|l|c|}
\hline No & \multicolumn{1}{|c|}{ NAMA-NAMA SANTRI } & $\begin{array}{c}\text { NILAI SETELAH } \\
\text { MENGGUNAKAN } \\
\text { MEDIA BONEKA } \\
\text { TANAGAN }\end{array}$ \\
\hline \hline 1 & Aditya Tama & 83,3 \\
\hline 2 & Alfin Syahrin Firza & 66,6 \\
\hline 3 & M. Azriansyah & 83,3 \\
\hline 4 & M. Nuzri Az-Zakkiy & 91,6 \\
\hline 5 & Muhammad Alfaroby & 83,3 \\
\hline
\end{tabular}


Vol. 1, No. 3 (Agustus 2019): 328-350

\begin{tabular}{|c|l|c|}
\hline 6 & Muhammad Al-Fares Andestra & 83,3 \\
\hline 7 & Muhammad Amru Yafi & 83,3 \\
\hline 8 & Muhammad Maulana Akbar & 83,3 \\
\hline 9 & Muhammad Naufal Fawwazz Aryanto & 100 \\
\hline 10 & Nizam Arif Rahman Hakim & 91.6 \\
\hline 11 & Rifki Abian & 75 \\
\hline 12 & Aisyah Aulia & 100 \\
\hline 13 & Bunga Mei Dinah & 100 \\
\hline 14 & Chintia Putri Awaliya & 91,6 \\
\hline 15 & Dina Alfiya Nur Rahmah & 83,3 \\
\hline 16 & Fairuz Azmi Dzakirah & 91,6 \\
\hline 17 & Hafizah Futri Sulaiman & 83,3 \\
\hline 18 & Keisyah Alfi Ramadhani & 100 \\
\hline 19 & Naila Hilyatil Asfiya & 91,6 \\
\hline 20 & Naura Kholidah & 75 \\
\hline 21 & Nur Jannatin Aliyah & 100 \\
\hline 22 & Tazkiya Zahrani Fatima & 92,6 \\
\hline 23 & Zafira & 66,6 \\
\hline
\end{tabular}

Dari data di atas dapat disimpulkan bahwa hasil bercerita santri pada mata pelajaran Sejarah Kebudayaaan Islam Materi Peristiwa Kelahiran Rasulullah SAW setelah penerapan dengan media Boneka Tangan dengan KKM (Kriteria Ketuntasan Minimal) sebesar 82 untuk pelajaran Sejarah Kebudayaan Islam, sebanyak 23 santri tersebut terdapat santri yang masih mendapat nilai dibawah KKM sedangkan terdapat santri yang mendapat nilai di atas KKM 20. Untuk mengelompokkan data menjadi beberapa kategori yakni kategori tinggi, sedang, dan rendah maka dapat menggunakan analisis TSR yang dapat diuraikan sebagai berikut:

1. Menyusun Data Mentah Penelitian

Menyusun data mentah penelitian bertujuan untuk mempermudah pengecekan data penelitian agar perhitungan yang salah dapat terhindarkan. Mengacu pada tabel 4.1 maka disusunlah data mentah sebagai berikut:

$\begin{array}{llllllll}83,3 & 66,6 & 83,3 & 91,6 & 83,3 & 83,3 & 83,3 & 83,3 \\ 100 & 91,6 & 75 & 100 & 100 & 91,6 & 83,3 & 91,6 \\ 83,3 & 100 & 91,6 & 75 & 100 & 91,6 & 66,6 & \end{array}$


2. Membuat Tabel Distribusi Frekuensi

Pembuatan Tabel Distribusi Frekuensi ini bertujuan untuk mempermudah proses perhitungan semisal mencari $\sum f X$ dan $\sum f X^{2}$, akan terasa sulit mengetahui jumlah tersebut jika tidak menggunakan tabel distribusi frekuensi, apapun tabel distribusi frekuensi tersebut adalah sebagai berikut:

Tabel. 3

Distribusi Frekuensi Hasil Penilaian Keterampilan Bercerita Santri Setelah Menggunakan Media Boneka Tangan

\begin{tabular}{|c|c|c|c|c|}
\hline $\mathbf{X}$ & $\mathbf{F}$ & $\mathbf{F X}$ & $\mathbf{X}^{\wedge} \mathbf{2}$ & $\mathbf{F X}^{\wedge} \mathbf{2}$ \\
\hline 66,6 & 2 & 133,2 & 4436,56 & 17742,24 \\
\hline 75 & 2 & 150 & 5625 & 22500 \\
\hline 83,3 & 8 & 666,4 & 6938,89 & 4440,89 \\
\hline 91,6 & 6 & 549,6 & 8390,56 & 302060,2 \\
\hline 100 & 5 & 500 & 10000 & 250000 \\
\hline & 23 & $1,999.2$ & 35390,01 & 3996800,64 \\
\hline
\end{tabular}

Dari tabel berikut dapat diketahui FX adalah $\left(\sum \mathrm{FX}=1999,2\right)$ dan jumlah $\mathrm{FX}^{2}\left(\sum \mathrm{FX}^{2}=3996800,64\right)$, setelah diketahui nilai tersebut maka dapat dicari mean dan standar daviasinya.

3. Mencari Mean dan Standar Davisi

Mencari mean dan standar daviasi ini bertujuan untuk memudahkan dalam menghitung rumus TSR pada langkah selanjutnya

a) Mencari Mean $\mathrm{X}_{2}$ :

$$
\mathrm{M}_{\mathrm{X}}=\frac{\sum f X}{N}=\frac{1999,2}{23}=86 \text { dibulatkan } 8
$$

b) Mencari Standar Deviasi $\mathrm{X}_{2}$

$$
\begin{aligned}
\mathrm{SD}_{\mathrm{X}} & =\frac{1}{N} \sqrt{(N)\left(\sum \mathrm{FX}^{2}\right)-\left(\sum \mathrm{FX}\right)^{2}} \\
& =\frac{1}{23} \sqrt{(23)(3996800.64)-(1999,2)^{2}} \\
& =\frac{1}{23} \sqrt{91926414,72-399680,64} \\
& =\frac{1}{23} \sqrt{87929619,08} \\
& =\frac{1}{23}(9,377,07945)
\end{aligned}
$$


Vol. 1, No. 3 (Agustus 2019): 328-350

$$
=9,3 \text { dibulatkan } 9
$$

Dari perhitungan di atas dapat kita ketahui bahwa $(\mathrm{Mx}=85)$ dan $(\mathrm{SDx}=10)$. Setelah nilai rata-rata (mean) dan standar deviasi (SD) diketahui, maka langkah selanjutnya adalah mengelompokkan nilai dalam tiga kategori.

4. Menghitung dan mengelompokkan nilai menjadi tiga kategori (tinggi, sedang, rendah) sebagai berikut:

a) Indikasi yang tergolong kategori tinggi

$$
\mathrm{M}+1 . \mathrm{SD}_{\mathrm{X}}=85+10=95 \text { ke atas (tinggi) }
$$

b) Indikasi yang tergolong kategori sedang nilai yang di antara nilai tertinggi dan terendah yaitu 76 - 94 (sedang)

c) Indikasi yang tergolong kategori rendah $\mathrm{M}-1 . \mathrm{SD}_{\mathrm{X}}=85-10=75$ ke bawah (rendah)

5. Menghitung persentase dari setiap kategori

Persentase dari jumlah nilai dalam setiap kategori dapat disajikan dalam tabel berikut:

Tabel. 4

Indikasi Hasil Keterampilan Bercerita Santri Yang Diajarkan Dengan Menggunakan Media Boneka Tangan

\begin{tabular}{|c|c|c|c|}
\hline No & Hasil Belajar & Frekuensi & Persentase \\
\hline 1 & Tinggi & 5 & $21,7 \%$ \\
\hline 2 & Sedang & 14 & $60,8 \%$ \\
\hline 3 & Rendah & 4 & $17,4 \%$ \\
\hline \multicolumn{2}{|c|}{ Jumlah } & $\mathbf{2 3}$ & $\mathbf{1 0 0 \%}$ \\
\hline
\end{tabular}

Dengan demikian dapat disimpulkan bahwa hasil keterampilan bercerita santri setelah menggunakan media boneka tangan pada mata pelajaran Sejarah Kebudayaan Islam di kelas III A Madrasah Ibtidaiyah AlIttifaqiah Indralaya pada kategori sedang yakni sebanyak 14 orang santri $(60,8 \%)$, kategori rendah yakni sebanyak 4 siswa $(17,4 \%)$ dan kategori tinggi sebanyak 5 santri $(21,7 \%)$ dari 23 santri yang menjadi sampel.

\section{B. Hasil keterampilan Bercerita Santri Dengan Tidak Menggunakan Media Boneka Tangan kelas kontrol}


Total responden pada postest kelas III Madrasah Ibtidaiyah adalah sebanyak 27 Santri. Dengan nama-nama sebagai berikut :

Tabel. 5

Nama Responden kelas III C

Madrasah Ibtidaiyah Indralaya Ogan Ilir Sumatera Selatan

\begin{tabular}{|c|l|c|}
\hline No & \multicolumn{1}{|c|}{ NAMA-NAMA SANTRI } & JENIS \\
& & KELAMAIN \\
\hline 1 & Ahmad Arya Al Aziz & Laki-Laki \\
\hline 2 & Ahmad Syahru Ramadhan & Laki-Laki \\
\hline 3 & Ahmad Syauqi (P) & Laki-Laki \\
\hline 4 & Akhdan El-Ziyad M. Nur & Laki-Laki \\
\hline 5 & M. Adhitya Pratama & Laki-Laki \\
\hline 6 & M. Alfin & Laki-Laki \\
\hline 7 & M. Zainul Fuad & Laki-Laki \\
\hline 8 & M. Zaki Al-Ghifari & Laki-Laki \\
\hline 9 & Muhammad Abril Satria & Laki-Laki \\
\hline 10 & Muhammad Bilfal & Laki-Laki \\
\hline 11 & Muhammad Fadhil & Laki-Laki \\
\hline 12 & Muhammad Faiz Al Qorni & Laki-Laki \\
\hline 13 & Muhammad Khalik Fajrindra & Laki-Laki \\
\hline 14 & Sammy Huzair Sobirin Putra & Laki-Laki \\
\hline 15 & Zahrahan & Laki-Laki \\
\hline 16 & Athifah Zahrotusyifa & Perempuan \\
\hline 17 & Atiyyah Talidzah Azziliah & Perempuan \\
\hline 18 & Aulia Anggraini $~$ & Perempuan \\
\hline 19 & Aurel Putri Budiman & Perempuan \\
\hline 20 & Ayesa Arrahmah ' & Perempuan \\
\hline 21 & Euis Putri Al Fiyyatuzzahirah & Perempuan \\
\hline 22 & Huriyatul Arsy'iah & Perempuan \\
\hline 23 & Khansa Wafi Kalyani & Perempuan \\
\hline 24 & Lailatul Al Fiana & Perempuan \\
\hline 25 & Maharani & Perempuan \\
\hline 26 & Nadhira Qothrunnada & Perempuan \\
\hline 27 & Rafeyfa Asyla & Perempuan \\
\hline & & \\
\hline
\end{tabular}

Hasil belajar siswa dengan tidak menggunakan media Boneka Tangan ini didapat dari nilai hasil tes berupa aspek-aspek keterampilan bercerita santri yang dipraktekkan oleh santri sendiri. Berdasarkan analisis data hasil keterampilan 
Vol. 1, No. 3 (Agustus 2019): 328-350

bercerita santri yang diperoleh dan kemudian data tersebut akan di analisis untuk mengetahui kemampuan keterampilan bercerita santri. Hasil keterampilan bercerita santri tanpa menggunakan media boneka tangan, tersebut dapat dilihat pada tabel berikut:

Tabel. 6

Hasil Penilaian Keterampilan Bercerita Santri

Tanpa Menerapkan Media Boneka Tangan (Kelas Kontrol)

\begin{tabular}{|c|l|c|}
\hline No & \multicolumn{1}{|c|}{ NAMA SANTRI } & $\begin{array}{c}\text { NILAI YANG TIDAK } \\
\text { MENERAPKAN } \\
\text { MEDIA BONEKA } \\
\text { TANAGAN }\end{array}$ \\
\hline \hline 1 & Ahmad Arya Al Aziz & 50 \\
\hline 2 & Ahmad Syahru Ramadhan & 33.3 \\
\hline 3 & Ahmad Syauqi (P) & 50 \\
\hline 4 & Akhdan El-Ziyad M. Nur & 58,3 \\
\hline 5 & M. Adhitya Pratama & 75 \\
\hline 6 & M. Alfin & 75 \\
\hline 7 & M. Zainul Fuad & 66,6 \\
\hline 8 & M. Zaki Al-Ghifari & 75 \\
\hline 9 & Muhammad Abril Satria & 50 \\
\hline 10 & Muhammad Bilfal & 25 \\
\hline 11 & Muhammad Fadhil & 50 \\
\hline 12 & Muhammad Faiz Al Qorni & 50 \\
\hline 13 & Muhammad Khalik Fajrindra & 75 \\
\hline 14 & Sammy Huzair Sobirin Putra & 66,6 \\
\hline 15 & Zahrahan & 50 \\
\hline 16 & Athifah Zahrotusyifa & 50 \\
\hline 17 & Atiyyah Talidzah Azziliah & 66,6 \\
\hline 18 & Aulia Anggraini & 75 \\
\hline 19 & Aurel Putri Budiman & 50 \\
\hline 20 & Ayesa Arrahmah ' & 50 \\
\hline 21 & Euis Putri Al Fiyyatuzzahirah & 83,3 \\
\hline 22 & Huriyatul Arsy'iah & 83,3 \\
\hline 23 & Khansa Wafi Kalyani & 91,6 \\
\hline 24 & Lailatul Al Fiana & 58,3 \\
\hline 25 & Maharani & 58,3 \\
\hline 26 & Nadhira Qothrunnada & 50 \\
\hline 27 & Rafeyfa Asyla & 50 \\
\hline & & \\
\hline
\end{tabular}


Dari data di atas dapat disimpulkan bahwa hasil belajar santri pada mata pelajaran Sejarah Kebudayaan Islam materi Peristiwa Kelahiran Rasulullah SAW. Dengan tidak menggunakan media Boneka Tangan dengan KKM (Kriteria Ketuntasan Minimal) sebesar 82 untuk pelajaran Sejarah Kebudayaan Islam sebanyak 27 nilai paling tinggi sebesar 85 sedangkan nilai terendah adalah 50. Untuk mengelompokkan data menjadi beberapa kategori yakni kategori tinggi, sedang, dan rendah maka dapat menggunakan analisis TSR yang dapat diuraikan sebagai berikut:

1. Menyusun Data Mentah Penelitian

Menyusun data mentah penelitian bertujuan untuk mempermudah pengecekan data penelitian agar perhitungan yang salah dapat terhindarkan. Mengacu pada maka disusunlah data mentah sebagai berikut:

$\begin{array}{lllllll}50 & 33,3 & 50 & 58,3 & 75 & 75 & 66,6 \\ 75 & 50 & 25 & 50 & 50 & 75 & 66,6 \\ 50 & 50 & 66,6 & 75 & 50 & 50 & 83,3 \\ 83,3 & 91,6 & 58,3 & 58,3 & 50 & 50 & \end{array}$

2. Membuat Tabel Distribusi Frekuensi

Pembuatan Tabel Distribusi Frekuensi ini bertujuan untuk mempermudah proses perhitungan semisal mencari $\sum F X$ dan $\sum F X^{2}$, akan terasa sulit mengetahui jumlah tersebut jika tidak menggunakan tabel distribusi frekuensi, apapun tabel distribusi frekuensi tersebut adalah sebagai berikut:

Tabel. 7

Distribusi Frekuensi Hasil Ketrampilan Bercerita Dengan Tidak Menggunakan Media Boneka Tangan

\begin{tabular}{|c|c|c|c|c|}
\hline $\mathrm{X}$ & $\mathrm{F}$ & $\mathrm{FX}$ & $\mathrm{X}^{\wedge} 2$ & $\mathrm{FX}^{\wedge} 2$ \\
\hline 25 & 1 & 25 & 625 & 625 \\
\hline 33,3 & 1 & 33,3 & 1108,89 & 1108,86 \\
\hline 50 & 11 & 550 & 2500 & 302500 \\
\hline 58,3 & 3 & 174,9 & 3398,89 & 30590,01 \\
\hline
\end{tabular}


Vol. 1, No. 3 (Agustus 2019): 328-350

\begin{tabular}{|c|c|c|c|c|}
\hline 66,6 & 3 & 199,8 & 4435,56 & 39920,04 \\
\hline 75 & 5 & 375 & 5625 & 140625 \\
\hline 83,3 & 2 & 166,6 & 6938,86 & 17755.56 \\
\hline 91,6 & 1 & 91,6 & 8390,56 & 8390,56 \\
\hline & 27 & 1616,2 & 33022,79 & 551515,06 \\
\hline
\end{tabular}

Dari tabel berikut dapat kita ketahui jumlah FX adalah ( $\sum$ FX $=1616,2)$ dan jumlah $\mathrm{FX}^{2}\left(\sum \mathrm{FX}^{2}=551515,06\right)$, setelah diketahui nilai tersebut maka dapat dicari mean dan standar daviasinya.

3. Mencari Mean dan Standar Deviasi

Mencari mean dan standar daviasi ini bertujuan untuk memudahkan dalam menghitung rumus TSR pada langkah selanjutnya.

a. Mencari Mean Y :

$$
\mathrm{M}_{\mathrm{y}}=\frac{\sum F X}{N}=\frac{1616,2}{27}=59,85 \text { dibulatkan } 60
$$

b. Mencari Standar Deviasi Y

$$
\begin{aligned}
\mathrm{SD}_{\mathrm{y}} & =\frac{1}{N} \sqrt{(N)\left(\sum \mathrm{FX}^{2}\right)-\left(\sum \mathrm{FX}\right)^{2}} \\
& =\frac{1}{27} \sqrt{(27)(551515,06)-(1616,02)^{2}} \\
& =\frac{1}{27} \sqrt{1489096,62-2612102,24} \\
& =\frac{1}{27} \sqrt{12278804,18} \\
& =\frac{1}{27}(3,504,11247) \\
& =3,5 \text { dibulatkan } 3
\end{aligned}
$$

Dari perhitungan di atas dapat diketahui bahwa $(\mathrm{Mx}=71)$ dan $(\mathrm{SDx}=11)$. Setelah nilai rata-rata (mean) dan standar deviasi $(\mathrm{SD})$ diketahui, maka langkah selanjutnya adalah mengelompokkan nilai dalam tiga kategori.

4. Menghitung dan mengelompokkan nilai menjadi tiga kategori (tinggi, sedang, rendah) sebagai berikut:

a. Indikasi yang tergolong kategori tinggi

$$
\mathrm{M}+1 . \mathrm{SD}_{\mathrm{X}}=71+11=82 \mathrm{ke} \text { atas (tinggi) }
$$


b. Indikasi yang tergolong kategori sedang nilai yang di antara nilai tertinggi dan terendah yaitu 61-81 (sedang)

c. Indikasi yang tergolong kategori rendah

$\mathrm{M}-1 . \mathrm{SD}_{\mathrm{X}}=71-11=60$ ke bawah (rendah)

5. Menghitung persentase dari setiap kategori

Persentase dari jumlah nilai dalam setiap kategori baik tinggi, sedang, dan rendah dapat disajikan dalam tabel berikut:

Tabel. 8

Indikasi Hasil Keterampilan Bercerita Santri Yang Tidak Diajarkan Dengan Menggunakan Media Boneka Tangan

\begin{tabular}{|c|c|c|c|}
\hline No & Hasil Belajar & Frekuensi & Persentase \\
\hline 1 & Tinggi & 3 & $11,11 \%$ \\
\hline 2 & Sedang & 8 & $29,62 \%$ \\
\hline 3 & Rendah & 16 & $59,25 \%$ \\
\hline \multicolumn{2}{|r|}{ Jumlah } & 27 & $100 \%$ \\
\hline
\end{tabular}

Dengan demikian dapat disimpulkan bahwa hasil keterampilan bercerita santri yang tidak menggunakan media boneka tangan pada kelas III Madrasah Ibtidaiyah Al-Ittifaqiah Indralaya dalam kategori sedang yakni sebanyak 8 orang santri $(29,62 \%)$ dari 27 santri.

\section{Hasil Penilaian Ketrampilan Bercerita Santri Dengan Penerapan Media Boneka Tangan Dan Yang Tidak Menerapkan Media Dalam Pembelajaran}

Untuk menganalisis perbedaan antara hasil belajar yang diajarkan dengan media boneka tangan dengan hasil keterampilan bercerita yang tidak diajarkan dengan menggunakan media maka pembahasan tersebut dapat diuraikan dalam dua kategori, yakni pertama, perbedaan ditinjau dari analisis TSR yang perhitungannya telah diuraikan diatas, kedua, Perbedaan dengan menguji hipotesis yang akan dihitung dengan rumus t-test.

1. Hasil Belajar Siswa Antara Kelas Eksperimen Dan Kelas Kontrol Ditinjau Dari Analisis TSR (Tinggi, Sedang, Rendah)

Analisis TSR antara hasil belajar pada kelas eksperimen dan kelas kontrol telah diuraikan pada bagian terdahulu, rekap hasil analisis TSR baik 
Vol. 1, No. 3 (Agustus 2019): 328-350

pada kelas eksperimen maupun kelas kontrol dapat disajikan pada tabel berikut:

Tabel. 9

Indikasi Hasil Ketrampilan Bercerita Santri Pada

Kelas Eksperimen Dan Kelas Kontrol

\begin{tabular}{|c|c|c|c|c|c|}
\hline \multirow{2}{*}{ No } & \multirow{2}{*}{$\begin{array}{c}\text { Hasil Belajar } \\
\text { Siswa }\end{array}$} & \multicolumn{2}{|c|}{ Kelas Eksperimen } & \multicolumn{2}{c|}{ Kelas Kontrol } \\
\cline { 3 - 6 } & & Frekuensi & Persentase & Frekuensi & Persentase \\
\hline 1 & Tinggi & 5 & $21,7 \%$ & 3 & $18,52 \%$ \\
\hline 2 & Sedang & 14 & $60,8 \%$ & 8 & $59,26 \%$ \\
\hline 3 & Rendah & 4 & $17,39 \%$ & 16 & $22,22 \%$ \\
\hline & Jumlah & $\mathbf{2 3}$ & $\mathbf{1 0 0 \%}$ & $\mathbf{2 7}$ & $\mathbf{1 0 0 \%}$ \\
\hline
\end{tabular}

a. Analisis Nilai Tinggi Antara Kelas Eksperimen dan Kelas Kontrol

Dari tabel tersebut terlihat bahwa nilai tinggi pada kelas eksperimen lebih dari pada kelas kontrol yakni sebanyak 5 dari 23 orang siswa atau $21,7 \%$ sedangkan pada kelas kontrol terdapat 3 dari 27 orang siswa atau $11,11 \%$, kategori tinggi pada kelas kontrol tersebut juga hanya mencapai nilai 91,6 berbeda pada kelas eksperimen beberapa siswa mencapai nilai sempurna (100).

b. Analisis Nilai Sedang Antara Kelas Eksperimen dan Kelas Kontrol

Nilai sedang pada kelas eksperimen terdapat 14 orang siswa sedangkan pada kelas kontrol hanya terdapat 8 orang siswa, terlihat bahwa kelas eksperimen lebih dari pada kelas kontrol, namun jika diteliti kembali 14 dari 23 orang santri tersebut persentasenya $60.8 \%$ sedangkan 8 dari 27 orang siswa tersebut persentasenya mencapai 29,62 \%, lebih besar ketimbang pada kelas eksperimen.

c. Analisis Nilai Rendah Antara Kelas Eksperimen dan Kelas Kontrol

Pada kelas eksperimen maupun kelas kontrol jumlah siswa yang memiliki nilai pada kategori rendah yakni sebanyak 4 dari 23 orang santri dan pada kelas kontrol yakni 16 dari 27 orang santri. Jika dilihat pada persentase jumlah siswa 4 dari 23 orang santri tersebut memiliki 17,39\% sedangkan 16 dari 27 orang santri tersebut memiliki 59,25\%, nilai 
persentase ini menunjukkan bahwa jumlah siswa yang mendapat nilai rendah pada kelas kontrol lebih banyak dari pada kelas eksperimen.

Jika mengacu dari analisis TSR di atas maka dapat ditarik kesimpulan bahwa hasil belajar siswa dengan menggunakan media Boneka Tangan lebih tinggi dari hasil belajar siswa yang tidak menggunakan media Boneka Tangan ini membuktikan bahwa pembelajaran Sejarah Kebudayaan Islam materi Peristiwa Kelahiran Rasulullah SAW pada kelas III A di Madrasah Ibtidaiyah Al-Ittifaqiah Idralaya Ogan Ilir Sumatra Selatan, dengan penerapan Media Boneka Tangan jauh lebih baik untuk Mata pelajaran Sejarah Kebudayaan Islam. dengan tidak menggunakan media Boneka Tangan.

2. Hasil Keterampilan Bercerita Santri Antara Kelas Eksperimen Dan Kelas Kontrol Ditinjau Dari Uji Hipotesis

Mengetahui keterampilan bercerita santri setelah penerapan media boneka tangan sangatlah penting, karena dari hasil kemampuan akhir inilah dapat terlihat peningkatan yang terjadi setelah menggunakan media boneka tangan nilai kemampuan akhir keterampilan bercerita santri antara kelas eksperimen dan kontrol dengan mengacu pada pembahasan terdahulu dapat disajikan dalam Tabel berikut:

Tabel. 10

Hasil Keterampilan Bercerita Santri pada Kelas Eksperimen dan Kelas Kontrol

\begin{tabular}{|c|c|c|}
\hline No & $\begin{array}{c}\text { Nilai Keterampilan Bercerita } \\
\text { Santri Kelas Eksperimen } \\
\text { Dengan Menggunakan Media } \\
\text { Boneka Tangan }\end{array}$ & $\begin{array}{c}\text { Nilai Keterampilan Bercerita } \\
\text { Santri Kelas Eksperimen Tidak } \\
\text { Menggunakan Media Boneka } \\
\text { Tangan }\end{array}$ \\
\hline 1 & 83,3 & 50 \\
\hline 2 & 66,6 & 33,3 \\
\hline 3 & 83,3 & 50 \\
\hline 4 & 91,6 & 58,3 \\
\hline 5 & 83,3 & 75 \\
\hline 6 & 83,3 & 75 \\
\hline 7 & 83,3 & 66,6 \\
\hline 8 & 83,3 & 75 \\
\hline
\end{tabular}


Vol. 1, No. 3 (Agustus 2019): 328-350

\begin{tabular}{|c|c|c|}
\hline 9 & 100 & 50 \\
\hline 10 & 91,6 & 25 \\
\hline 11 & 75 & 50 \\
\hline 12 & 100 & 50 \\
\hline 13 & 100 & 75 \\
\hline 14 & 91,6 & 66,6 \\
\hline 15 & 83,3 & 50 \\
\hline 16 & 91,6 & 50 \\
\hline 17 & 83,3 & 66,6 \\
\hline 18 & 100 & 75 \\
\hline 19 & 91,6 & 50 \\
\hline 20 & 75 & 50 \\
\hline 21 & 100 & 83,3 \\
\hline 22 & 91,6 & 83,3 \\
\hline 23 & 66,6 & 91,6 \\
\hline 24 & - & 58,3 \\
\hline 25 & - & 58,3 \\
\hline 26 & - & 50 \\
\hline 27 & - & 50 \\
\hline
\end{tabular}

Dari tabel diatas dapat diketahui bahwa pada kelas Eksperimen terdapat 5 orang santri mendapatkan nilai sempurna (100) sedangkan pada kelas kontrol terdapat orang santri yang mendapat nilai tinggi yaitu 83,3. Untuk memudahkan pengecekan nilai hasil keterampilan bercerita santri yakni pada tabel 4.8 dengan mengacu pada pembahasan terdahulu, dapat disajikan dalam tabel 4.11 yaitu sebagai berikut:

Tabel. 11

Rekap Nilai Keterampilan Bercerita Santri Pada Kelas Eksperimen Dan Kelas Kontrol

\begin{tabular}{|c|c|c|c|c|c|}
\hline \multirow{2}{*}{ Kelompok } & \multirow{2}{*}{$\mathbf{N}$} & \multicolumn{3}{|c|}{ Nilai } & \multirow{2}{*}{$\begin{array}{l}\text { Standar } \\
\text { Daviasi }\end{array}$} \\
\hline & & Tertinggi & Terendah & Rata-rata & \\
\hline Eksperimen & 23 & 100 & 65 & 85,43 & 9 \\
\hline Kontrol & 27 & 85 & 25 & 71,29 & 11 \\
\hline
\end{tabular}

Dari data tersebut dapat diketahui nilai rata-rata dan standar daviasi dari masing-masing kelas, terlihat bahwa kelas eksperimen memiliki nilai rata-rata lebih tinggi dari kelas kontrol. Dari sini dapat disimpulkan bahwa pembelajaran Sejarah Kebudayaan Islam dengan menggunakan media boneka tangan lebih baik 
dari pada tidak menggunakan media-media boneka tangan, namun untuk membuktikan bahwa perbedaan tersebut adalah perbedaan yang signifikan atau tidak perlu menghitungnya dengan uji hipotesis menggunakan t-test. Setelah mengetahui nilai rata-rata dan simpangan baku di atas, selanjutnya akan dilakukan langkah-langkah sebagai berikut:

a. Mencari Standar Eror of Mean

$$
\begin{aligned}
& S M_{M 1}=\frac{S D_{1}}{\sqrt{N_{1}-1}}=\frac{9}{\sqrt{23-1}}=\frac{9}{4.69}=1,91 \\
& S M_{M 2}=\frac{S D_{2}}{\sqrt{N}_{2}-1}=\frac{11}{\sqrt{27-1}}=\frac{11}{5,09}=2,16
\end{aligned}
$$

Setelah diketahui Standar Eror dari masing-masing mean maka langkah selanjutnya adalah mencari Standar Eror Perbedaan dari kedua mean di atas dengan rumus sebagai berikut:

b. Mencari Standar Eror Perbedaan

$$
\begin{aligned}
S E_{M 1-M 2} & =\sqrt{S E_{M 1}^{2}+S E_{M 2}^{2}} \\
& =\sqrt{1.91^{2}+2,16^{2}} \\
& =\sqrt{3,64+4,66} \\
& =\sqrt{8.3}=2,88
\end{aligned}
$$

Dari perhitungan di atas dapat kita ketahui bahwa Standar Eror Perbedaan dari kedua mean tersebut adalah sebesar 2, 88 setelah mengetahui Standar Eror Perbedaan tersebut langkah selanjutnya adalah menguji hipotesis dengan ketentuan sebagai berikut:

1) Jika to sama dengan atau lebih besar dari pada harga kritik "t" yang tercantum dalam tabel (diberi lambang $\mathrm{t}_{\mathrm{t}}$ ), maka Hipotesis Nihil yang mengatakan tidak adanya perbedaan mean dari kedua sampel, ditolak; berarti perbedaan mean dari kedua sampel itu adalah perbedaan yang signifikan.

2) Jika $t_{0}$ lebih kecil dari $t_{t}$, maka Hipotesis Nihil yang menyatakan tidak adanya perbedaan mean dari kedua sampel yang bersangkutan, disetujui 
Vol. 1, No. 3 (Agustus 2019): 328-350

berarti perbedaan mean dari kedua sampel ini bukanlah perbedaan mean yang signifikan, melainkan perbedaan yang terjadi hanya secara kebetulan saja (by chance) sebagai akibat Sampling Eror. ${ }^{19}$

Uji Hipotesis Menguji hipotesis ini bertujuan untuk mengetahui perbedaan antara hasil Keterampilan bercerita santri dengan penerapan media boneka tangan dengan hasil keterampilan bercerita santri yang tidak menggunakan media boneka tangan bertaraf signifikan atau tidak. Dengan mengacu pada buku statistik karya Anas. ${ }^{20}$ Maka untuk menguji hipotesis tersebut digunakan rumus sebagai berikut:

$$
t=\frac{M_{1}-M_{2}}{S E_{M 1-M 2}}=\frac{85,43-71,29}{2,88}=\frac{14,14}{2,88}=4,90
$$

Berdasarkan perhitungan di atas, diketahui bahwa thitung sebesar 4, 90 yang kemudian dibandingkan dengan $t_{\text {tabel }}$ dengan ketentuan df atau $\mathrm{db}=\left(\mathrm{N}_{1}+\mathrm{N}_{2}-2\right)=$ $(23+27-2)=48$ (konsultasi Tabel Nilai “t”). Oleh karena df 48 tidak terdapat pada tabel nilai "t", maka df 50 ditetapkan sebagai df yang mendekati. Dengan df 50 diperoleh $t_{\text {tabel }}$ sebagai berikut:

1) Pada taraf signifikasi $5 \%=2,01$

2) Pada taraf signifikasi $1 \%=2,68$

Dengan membandingkan besarnya " $\mathrm{t}$ " yang diperoleh dalam perhitungan ( $\left.\mathrm{t}_{\text {hitung }}=4,90\right)$ dan besarnya " $\mathrm{t}$ " yang tercantum pada tabel nilai $\mathrm{t}(5 \%=2,01$ dan $1 \%$ $=2,68)$ maka dapat diketahui bahwa $t_{\text {hitung }}$ adalah lebih besar dari pada $t_{\text {tabel }}$ yaitu: $2,01<4,69>2,68$. Karena thitung yang diperoleh dalam perhitungan adalah lebih besar dari pada $t_{\text {tabel }}$ baik pada taraf signifikasi 5\% maupun pada taraf signifikasi $1 \%$, maka Hipotesis Alternatif diterima. Berarti antara hasil keterampilan bercerita santri dengan menggunakan media boneka tangan pada kelas eksperimen dan hasil belajar dengan tidak menggunakan media boneka tangan pada kelas kontrol terdapat perbedaan yang signifikan.

\footnotetext{
${ }^{19}$ Anas Sudijono, Pengantar statistik pendidikan, (Jakarta: Rajawali Press, 2014), hlm. 274

${ }^{20}$ Ibid.,
} 


\section{SIMPULAN}

Berdasarkan analisis yang telah dilakukan maka penelitian ini dapat disimpulkan Hasil penilaian keterampilan bercerita santri yang diajarkan dengan menggunakan media boneka tangan mata pelajaran Sejarah Kebudayaan Islam di Madrasah Ibtidaiyah Al-Ittifaqiah Indralaya tergolong sedang sebanyak 14 dari 23 orang santri (60,8\%), dengan nilai tinggi sebanyak 5 dari 23 santri (21,7\%), sedangkan 4 santri memiliki nilai rendah atau $(17,39 \%)$.

Berdasarkan analisis Hasil penilaian keterampilan santri yang tidak diajarkan dengan menggunakan media boneka tangan di Madrasah Ibtidaiyah Al-Ittifaqiah Indralaya pada mata pelajaran Sejarah Kebudayaan Islam di tergolong sedang sebanyak 8 dari 27 santri (29,62\%), dengan nilai tinggi sebanyak 3 dari 27 santri atau $(11,11 \%)$, dan siswa dengan nilai rendah sebanyak 16 dari 27 santri $(59,25 \%)$

Berdasarkan hasil yang diperoleh dari lapangan dan perhitungan menggunakan Uji TSR dapat disimpulkan bahwa : pertama keterampilan bercerita santri kelas kontrol dalam proses pembelajaran yang terkategori tinggi sebanyak 3 santri $(18,52$ $\%$.) dan nilai terkategori sedang sebanyak 8 santri $(59,26 \%)$ adapun nilai terkategori rendah sebanyak 16 santri $(22,22 \%)$ adapun kedua keterampilan bercerita santri kelas eksperimen dalam proses pembelajaran dikategorikan tinggi sebanyak 5 santri $(21,7$ $\%)$ dan yang terkategori sedang sebanyak 14 santri $(60,8 \%)$ dan yang terkategori rendah sebanyak 4 santri $(17,39 \%)$, ketiga hasil penilaian keterampilan Bercerita santri yang signifikan. ketrampilan bercerita santri kelas kontrol dan kelas eksperimen pada mata pelajaran Sejarah Kebudayaan Islam pada Materi Peristiwa Kelahiran Rasulullah di Madrasah Ibtidaiyah Al-Ittifaqiah Indralaya dilihat dari mean dari nilai mentah yang di dapat dari aspek penilaian keterampilan bercerita. Untuk mengetahui bagaimana perbedaan menggunakan rumus $r_{X Y}$. dari hasil hitung $r_{X Y}$ membuktikan bahwa hasil $\mathrm{r}_{\text {hitung }}$ lebih besar dari $\mathrm{r}_{\text {table }}$ baik pada taraf signifikan 5\% dan $1 \%(20,1<$ 4,69 > 2,68). Hal ini menunjukkan bahwa "ada perbedaan yang signifikan antara keterampilan bercerita kelas eksperimen dan kelas kontrol dengan penerapan media boneka tangan di kelas III Madrasah Ibtidaiyah Al-Ittifaqiah Indralaya. 
Vol. 1, No. 3 (Agustus 2019): 328-350

\section{DAFTAR PUSTAKA}

Ahmad Rofi'uddin \& Darmiyati Zuhdi. 1998. Pendidikan Bahasa dan Sastra Indonesia di Kelas Tinggi. Jakarta: Depdikbud RI

Ali Hamzah dan Muhlisrarini, 2014. Perencanaan Dan Strategi Pembelajaran Matematika. Jakarta: Rajawali Pers

Anas Sudijono. 2015. Pengantar Evaluasi Pendidikan. Jakarta: PT Raja Grafindo Persada

Burhan Nugiyantoro. 2001. Penilaian Dalam Pengajaran Bahasa dan Sastra. Yogyakarta: BPFE

Daryantio,2016, media pembelajaran, Yogyakarta: Gava Media

Djago Tarigan, dkk, 1990. Materi Pokok Pendidikan Bahasa Indonesia I . (Jakarta : P2LPTK PT Depdikbud

Haryadi dan Zamzami, 1997. PeningkatanKeterampilan Berbahasa Indonesia. Jakarta : Direktorat Jendral Pendidikan Tinggi

Kementrian Agama, Peraturan Mentri Agama Republik Indonesia Tentang Kurikulum Madrasah 2013 Mata Pelajaran Pendidikan Agama Islam dan Bahasa Arab, No.000912, th. 213, p. 49

Nana Sudjanah dan Ahmad Rivai, 1991. Media Pengajaran, (Bandung: CV. Sinar Baru

Saleh Abbas, 2006. Pembelajaran Bahasa Indonesia yang Efektif di Sekolah Dasar. Jakarta : Direktorat Jendral Pendidikan Tinggi

Sugiyono. 2011. Metode Penelitian Kuantitatif, Kualitatif dan R\&D, Bandung: CV. Alfabeta

WJS Poerwodarminto. 1984. Pusat Pembinaan dan Pengembangan Bahasa Depdikbud. Jakarta : Balai Pustaka 